\title{
Paralinguistic Characteristics of Children with High-Functioning Autism Spectrum Disorder in Conversation: Expert Perceptual Evaluation and Acoustic Analysis
}

\author{
Jieun Choi ${ }^{\mathrm{a}}$, YoonKyoung Lee \\ aDepartment of Speech-Language Pathology and Audiology, Graduate School of Hallym University, Chuncheon, Korea \\ ${ }^{b}$ Division of Speech Pathology and Audiology, Hallym University, Chuncheon, Korea
}

Correspondence: YoonKyoung Lee, $\mathrm{PhD}$ Division of Speech Pathology and Audiology, Hallym University, 1 Hallimdaehak-gil, Chuncheon 24252, Korea

Tel: $+82-33-248-2219$

Fax: +82-33-256-3420

E-mail: ylee@hallym.ac.kr

Received: October 20, 2019

Revised: November 25, 2019

Accepted: November 25, 2019

This article is an excerpt from the PhD's thesis of the first author (2019).
Objectives: The purpose of this study was to examine the paralinguistic characteristics of children with high-functioning autism spectrum disorder (HFASD) through acoustic analysis, and to investigate whether an expert can perceive the paralinguistic characteristics of HFASD using a perceptual rating scale. Methods: The participants were a total of 51 children: 17 HFASD children and 34 typically developing (TD) children (17 matched with chronological age and 17 matched with language age). All children's utterances used for acoustic analysis were extracted from three declarative sentences and two interrogative sentences. The mean pitch, pitch range, loudness, and speech rate were analyzed. For the perceptual evaluation, the 51 conversation samples were randomly numbered according to a set proportion between the two groups. A perceptual rating scale was performed by 6 speechlanguage pathologies to measure the paralinguistic characteristics. Results: The results were as follows. In acoustic analysis, there were no significant differences in mean pitch, pitch range, intensity, and speech rate measured with Computerized Speech Lab between the two groups. In perceptual evaluation, there were no significant differences in speech rate and intensity between the two groups, but the HFASD group scored significantly higher in changes of intensity, pitch, and intonation compared to the TD group. Conclusion: We discussed paralinguistic characteristics of children with HFASD based on these results.

Keywords: Perceptual evaluation, Acoustic analysis, High-functioning autism spectrum disorder, Paralinguistic, Conversation
대화는 두 사람 이상이 서로 이야기를 주고 받는 양방향 의사소 통이다(Heo \& Lee, 2012; Nippold, Hesketh, Duthie, \& Mansfield, 2005). 대화는 매우 어린 영유아 시기부터(Lee \& Lee, 2013) 학령기 (Park, Choi, \& Lee, 2017), 청소년기(Yang, Lee, Choi, \& Yoon, 2018) 까지 계속해서 발달하는 중요한 능력이라고 볼 수 있다. 대부분의 사람들은 다른 사람들과 정보를 얻거나 나누기 위해, 생각을 표현 하고 관계를 유지하기 위해 대화를 하는데, 대화는 주로 언어를 통 해 이루어진다. 하지만 언어로 충분히 의도 전달이 되지 않는 경우 도 발생하기 때문에 의도를 좀 더 정확하게 효율적으로 전달하기
위해서는 준언어적인 측면이 필요하다(Meharabian, 1981).

준언어적 측면은 언어에 부수적으로 표현되는 것으로 준언어적 특성을 살펴보기 위한 선행연구들은 대부분 음도, 음도 범위, 강도, 말속도를 중심으로 살펴보았다(McAlpine et al., 2014; Nadig \& Shaw, 2012; Sharda et al., 2010). 평균 음도와 강도는 목소리 높낮이 와 크기를 반영해 주는 것으로 대화 시 현재 정서상태를 나타내거 나 상대방에게 의도를 강조해 줄 수 있으며, 말속도는 말소리 길이 를 짧고 길게 변화시킴으로써 전달하고자 하는 내용을 강조해준 다. 뿐만 아니라 음도 범위는 주로 억양에 영향을 주며 발화를 극적 
으로 전달하거나 정서를 표현하기 위해 사용될 수 있어 대화 시 중 요한 역할을 한다(Shin, Choi, Kim, \& Lee, 2015). 따라서 준언어적 측면은 화자의 의도를 강조하여 표현해주며, 청자에게 자신의 느낌 이나 태도를 전달하는데 도움을 주는 등 의사소통에서 매우 중요 하다고 볼 수 있다(Shriberg et al., 2001).

고기능 자폐스펙트럼장애(high-functioning autism spectrum disorder, HFASD) 아동에게 관찰되는 특징 중 하나는 비전형적인 운율이다. 비전형적인 운율 특성으로 인해 상대방과의 대화시 의미 전달에 부정적인 영향을 줄 수 있고, 더 나아가 의사소통 의도가 제 대로 전달되는 것을 방해할 수 있다(Diehl, Watson, Bennetto, McDonough, \& Funlogson, 2009; Shriberg et al., 2001). 또한 다른 사람 과의 상호작용 시 사회적으로 부정적인 인상을 줄 수 있어, 의사소 통에 어려움을 줄 가능성이 높다(Paul, Orlovski, Marcinko, \& Volkmar, 2009; Van Bourgondien \& Woods, 1992).

자폐스펙트럼장애 아동은 많은 연구들을 통해 비정상적인 운 율, 과도한 음도 변화와 높은 평균 음도, 느린 말속도 등 다양한 비 전형적인 준언어적 특성들이 보고되어왔다(Nadig \& Shaw, 2012; Diehl et al., 2009; Shriberg et al., 2001). 자폐스펙트럼장애 아동의 준언어적 특성을 살펴보는 방법으로는 기계를 사용하여 객관적 수 치로 평가하는 음향학적 분석 방법과, 다른 사람들이 해당 음성을 척도를 사용하여 어떻게 지각되는지 주관적으로 평가하는 지각적 평가 두 가지가 있다. Shin 등(2015)은 국외에서 자폐스펙트럼장애 의 음향학적인 운율 특성을 살펴본 논문 15 편에 대해 메타 분석을 실시하였는데, 자폐스펙트럼장애 집단은 일반아동 집단에 비해 음 도, 강도, 말속도에서 유의한 차이를 보이는 것으로 나타났다. 국내 에서도 자폐스펙트럼장애 아동은 일반아동보다 높은 음도(Jung \& Seong, 2007; Lim \& Sim, 2009), 넓은 음도 범위를 보이는 것으로 보고되었다(Shin, Choi, \& Lee, 2016).

앞서 살펴본 바와 같이 자폐스펙트럼장애 아동은 음향학적 분 석을 통해 비전형적인 운율적 특성을 보이는 것으로 보고되었다. 하지만 이러한 객관적 수치에서의 차이는 다른 사람들의 지각에 미 치는 영향과는 다를 수 있다(Ferrand, 2011). 이러한 이유로 Shin 등(2016)은 7-9세 고기능 자폐스펙트럼장애 아동을 대상으로 음향 학적 분석과 청지각적 평가를 실시하여 준언어적 특성을 살펴보았 다. 그 결과 음향학적 분석 시, 자폐스펙트럼장애 아동은 일반아동 에 비해 유의하게 더 넓은 음도 범위를 보이는 것으로 나타났으며, 일반성인이 청지각적 평가를 실시하였을 때에도 일반아동에 비해 자폐스펙트럼장애 아동이 유의하게 더 높은 음도, 넓은 음도 범위 를 갖는 것으로 지각되었다. Nadig와 Shaw (2012)는 8-14세 고기능 자폐스펙트럼장애 아동을 대상으로 살펴보았을 때, 음향학적 분
석 시, 자폐스펙트럼장애 아동은 일반아동에 비해 음도 범위가 유 의하게 큰 것으로 나타났으나 일반성인들은 지각적으로 유의한 차 이를 느끼지 못하는 것으로 나타났다.

앞서 살펴본 선행연구들은 모두 청지각적 평가자들을 언어병리 학 전공 학부생으로 기본적인 말소리 개념을 이해하는 자로 선정 하여 실시하였으며, 청지각적 평가 척도 또한 단순히 음도나 음도 변화, 말속도와 같은 측정치에서 높고 낮은지, 느리고 빠른지와 같 은 이분법적인 부분으로만 측정을 하였다. 자폐스펙트럼장애 아동 의 비전형적인 운율 특성은 청자에 의해 부정적으로 지각될 수 있 기 때문에 선행연구들처럼 단순히 준언어적 측정치가 어떠한지를 평가하는 것이 아니라 대화에 미치는 영향이 어느 정도 인지를 확 인하는 것이 중요하다고 볼 수 있다. 또한 자폐스펙트럼장애 아동 의 비전형적인 운율 특성은 언어능력이 향상되더라도 지속되는 경 향이 있으므로(McCann, Peppe, Gibbon, O’Hare, \& Rutherford, 2007) 자폐스펙트럼장애 교육 및 치료의 경험이 있는 전문가가 지 각하였을 때 준언어적 측면에서의 특성이 어떠한지 살펴본다면 자 폐스펙트럼장애 아동의 준언어적 측면의 체계적인 평가와 중재를 하는데 도움이 될 수 있을 것으로 생각된다.

따라서 본 연구는 학령기 고기능 자폐스펙트럼장애 아동을 대 상으로 대화에서의 준언어적 특성을 음향학적 분석을 통해 살펴 보고, 이러한 특성들이 다른 사람들에게도 어떻게 지각되는지 알 아보기 위해 전문가를 대상으로 지각적 평가를 실시하여 확인하고 자하였다.

\section{연구방법}

\section{연구대상}

대화 자료 수집

본 연구의 대상은 강원 및 경기 지역 초등학교에 재학 중인 고기 능 자폐스펙트럼장애(HFASD) 아동 17명, 일반아동 34 명(언어연령 일치 일반아동 17 명, 생활연령 일치 일반아동 17 명)으로 총 51 명이 다. 본 연구에서는 대화능력이 언어능력과 더불어 아동의 생활경 험 능력에도 영향을 받기 때문에(Hoff, 2009), 언어연령을 일치시킨 일반아동뿐만 아니라 생활연령을 일치시킨 일반아동을 함께 포함 하였다.

고기능 자폐스펙트럼장애 아동은 (1) 대학병원이나 종합병원 소 아정신과 전문의에 의해 자폐스펙트럼장애로 진단받거나 의심된 다고 보고된 아동 중, (2) Autism Diagnostic Observation Schedule-Second Edition (ADOS-2; Lord et al., 2012) module 3 결과 전 체 알고리즘 점수가 7점 이상으로 자폐스펙트럼에 해당하고, 사회 
적 의사소통 설문지(SCQ; Yoo, 2008) 검사 결과 자폐스펙트럼장애 기준에 해당하는 15 점 이상이며, (3) 한국 비언어 지능검사-2(Korean version of Comprehensive Test of Nonverbal Intelligence second edition, K-CTONI-2; Park, 2014)의 지능지수가 80 이상이고, (4) 수 용·표현어휘력검사(Receptive \& Expressive Vocabulary Test, REVT; Kim, Hong, Kim, Jang, \& Lee, 2009) 결과가 10 백분위수 이상, 학령 기 아동 언어검사(Language Scale for School-aged Children, LSSC; Lee, Heo, \& Jang, 2015) 중 수용언어 및 표현언어 능력과 높은 상관 을 보인 ‘단락듣기 이해’, ‘문법 판단 및 수정' 문항검사 결과 환산점 수 10점 내외(-1 SD 이상)에 해당하며, (5) 상대방과의 대화에서 신 체적 장애(시각. 청각 장애, 신체적 결함, 심한 행동장애)로 인해 방 해 받지 않는 아동으로 선정하였다.

일반아동은 (1) 부모와 주양육자, 교사에 의해 발달이 정상적으 로 이루어졌다고 보고된 아동들로, (2) 고기능 자폐스펙트럼장애 아동과 일대일로 일치시켰을 때 같은 학년에 속하는 아동 1 명과 REVT 표현언어 원점수가 같은 연령대에 해당하는 1 명 각 2 명씩 매 치하였고, (3) 시각 및 감각장애나 심각한 정서 문제를 보이지 않는 아동으로 선정하였다.

모든 아동의 부모님들에게 검사 실시 전 부모동의서를 얻은 후, 모든 절차를 진행하였다. 고기능 자폐스펙트럼장애 아동 집단과 일반아동 집단은 REVT-E 등가연령, LSSC 하위문항, K-CTONI-2 지능지수에서 유의한 차이가 없었고, SCQ에서만 유의한 차이가 있었다. 연구대상의 기본정보는 Table 1 과 같다.

\section{지각적 평가}

지각적 평가를 통해 고기능 자폐스펙트럼장애 아동의 대화에서 의 준언어적 특성을 확인하기 위하여 고기능 자폐스펙트럼장애 아 동 교육 또는 치료 경험이 최소 3 년인 언어재활사 6 명을 평가자로 선 정하였다. 전체 평가자의 임상경력은 최소 3 년에서 최대 18 년까지 평 균 8 년이었으며, 평가자 중 2 명은 언어병리학 박사, 4 명은 언어병리 학 석사였다. 평가자 6 명 중 1 명의 경력이 3 년이나 본 평가자는 자폐 스펙트럼장애 아동들을 주로 보는 임상현장에서 일을 하고 있었다.

\section{자료수집 도구}

\section{대화 자료}

대화 자료는 연구자와 1:1로 조용한 방에서 한림 대화-화용평가 프로토콜(Lee \& Choi, in press) 중 대화 절차를 사용하여 대화 자 료를 수집하였다(Park et al., 2017). 대화는 아동에게 익숙한 '가정 생활, 학교생활, 기타/친구'의 주제로 진행하였다. 연구자는 모든 아 동에게 대화상대자 요인을 최소화하면서 자연스러운 대화를 유지
Table 1. Participants' information

\begin{tabular}{llcc}
\hline & HFASD (N=17) & TD (N=34) & $t$ \\
\hline Chronological age (mo) & $98.83 \pm 18.59$ & $99.31 \pm 20.70$ & \\
Autism diagnostic test & & & \\
SCO & $18.28 \pm 4.47(15-31)$ & $1.63 \pm 1.90(0-7)$ & $18.437^{* * *}$ \\
ADOS-2 total score & $11.94 \pm 3.56(8-20)$ & - & - \\
Language test & & & \\
REVT-E language age & $88.72 \pm 22.16$ & $92.25 \pm 23.38$ & -.522 \\
LSSC USP converted score & $8.57 \pm 2.70$ & $11.07 \pm 3.27$ & -1.742 \\
LSSC GEJ converted score & $8.86 \pm 1.68$ & $10.43 \pm 1.70$ & -2.008 \\
$\quad$ LSSC GER converted score & $8.71 \pm 1.25$ & $10.71 \pm 2.46$ & -2.004 \\
Intelligence test & & & \\
K-CTONI-2 & $99.56 \pm 9.96$ & $99.28 \pm 13.62$ & .075 \\
K-WISC III or IV & $96.23 \pm 14.62$ & - & - \\
\hline
\end{tabular}

Values are presented as mean \pm SD (range).

HFASD = high functioning autism spectrum disorders; TD=typical development; ADOS-2 = Autism Diagnostic Observation Schedule 2nd edition; REVT = Receptive \& Expressive Vocabulary Test (Kim, Hong, Kim, Jang, \& Lee, 2009); LSSC=L Language Scale for School-aged Children (Lee, Heo, \& Jang, 2015); USP = understanding spoken paragraph; GEJ = grammatical error judgement; GER=grammatical error revision; K-CTONI-2 = Korean version of Comprehensive Test of Nonverbal Intelligence second edition (Park, 2014); K-WISC-III=Korean Wechsler Intelligence Scale for Children-III (Kwak, Park, \& Kim, 2001).

${ }^{* * *} p<.001$.

하기 위해 정해진 반응 절차에 따라 대화를 실시하였다(Choi \& Lee, 2013, 2015, 2019; Park et al., 2017).

\section{지각적 평가}

지각적 평가는 Choi와 Lee (2019)의 연구에서 사용한 대화 지각 적 평정 척도를 활용하였다. 대화 지각적 평정 척도는 대화 관련 문 헌과 자폐스펙트럼장애 아동의 대화 선행문헌, 자폐스펙트럼장애 아동의 대화 척도—예를 들면 PRS (Landa et al., 1992), CCC-2 (Bishop, 2003), TOPICC (Adams et al., 2012), Pragmatic Protocol (Prutting \& Kittchner, 1987)—등을 종합하여 작성되었다. 평정 척도 질 문은 자폐스펙트럼장애에게 보고되는 비정상적인 행동들을 반영 한 항목으로 구성되었으며, 크게 대화의 언어적 요인(대화기술), 준 언어적 요인, 비언어적 요인의 3가지 영역으로 분류되었다. 문항의 척도는 4점 평정 척도로 최하 0 점에서 최고 3 점이며, 점수가 높아질 수록 특정 항목에서 적절하지 못하다는 것을 의미하였다. 본 연구 에서는 척도의 일부인 준언어적 요인에 대한 말속도, 목소리 크기, 목소리 크기변화, 목소리 높낮이, 억양의 5 가지 문항만을 활용하였 다(Appendix 1).

\section{연구 절차}

대화를 진행하기 전 각 아동의 부모님에게 녹음 및 녹화에 대한 
사전 동의를 받은 후 아동의 대화를 진행하였다. 모든 대화는 아동 이 치료를 받고 있는 치료실이나 아동 집의 독립된 장소에서 Tantam, Holmes와 Cordess (1993)의 연구를 참고하여 디지털 캠코더 2 대와 녹음기를 이용하여 녹음 및 녹화하였다. 아동과의 대화는 아동의 옷에 걸 수 있는 선걸이형 마이크와 디지털 보이스 레코더 를 사용하여 녹음하였으며, 녹음 시 마이크는 아동의 입에서 약 15 $\mathrm{cm}$ 정도 떨어진 곳에 위치하도록 하고 핀을 이용하여 옷에 고정시 킨 후(Van Santen, Prud'hommeaux, Black, \& Mitchell, 2010) 실시 하였다.

\section{음향학적 분석}

음향학적 분석을 위해 아동의 발화가 녹음된 mp3 파일은 GoldWave version 6.17을 이용하여 wav 파일로 변환한 후, 샘플링 속도 (sampling rate) $11,000 \mathrm{~Hz}$ 에서 디지털화하였다. 녹음된 대화에서 검사자의 발화를 제외한 아동의 발화만을 추출한 음성파일로 편 집하였고, CSL (Computerized Speech Lab, model 4150B; KayPENTAX, Montvale, NJ, USA)을 사용하여 $200 \mathrm{~ms}$ 이상의 쉼 구간을 수동적으로 조정하여 삭제하였으며, 단어 반복, 기침, 목청 가다듬 기 등의 비언어적 소리도 삭제하여 유창한 발화만을 남겨두었다 (Seo, 2013). 아동의 발화에서 가장 긴 발화 5개(3어절)를 선택하고 (Nadig \& Shaw, 2012), 문장유형에 따라 운율 특성이 달라지기 때 문에(Shin et al., 2016) 추출한 발화의 문장유형은 모두 평서문 3개 와 의문문 2 개로 통제하였다.

\section{대화 지각적 평정 척도}

51 명의 대화 자료는 집단이 무작위로 섞이도록 한 후 1 번부터 51 번까지 번호를 부여하였다. 이때 무작위로 부여된 번호가 한 집단 에 쏠리는 경우 한 명의 평가자가 한 집단의 대화 자료 샘플을 분석 할 가능성이 높기 때문에 집단 간 비율을 조절하여 번호를 부여하 였다. 2 개의 캠코더로 녹화된 총 51 명의 대화 자료 동영상은 '곰앤컴 퍼니사의 동영상 캠퍼/녹화 프로그램인 곰캠을 활용하여 두 영상 이 동시에 재생되도록 편집하였다. 동영상은 검사자가 아동에게 대 화 절차에 대해 설명하는 도입 부분을 제외하고 2 개 영상의 시간축 을 확인하여 동일한 시간으로 재생되도록 편집하였다.

평가를 실시하기 전 평자가들에게 평정 지침을 숙지하도록 평정 척도에 대한 설명과 교육을 실시하였다. 평가자별로 평정 지침에 대 해 숙지가 되었다고 판단되면, 무작위로 부여된 대화 자료를 보고 개별적으로 평가하도록 하였다. 1 개의 대화 자료는 10 분 내외로, 1 개의 대화 자료 영상을 본 후 약 1 분간 해당 아동의 평가 척도를 완 성하도록 하였다.
전체 51 개의 자료 중 4 개의 자료는 모든 전문가가 공통적으로 분 석하도록 하였다. 4 개의 자료를 제외한 대화 샘플 자료는 2 명의 전 문가가 평가하여 개인차를 줄이도록 하였으며(Yoon, Lee, \& Sim, 2000), 1 명의 전문가에게 모든 대화 샘플을 제시하여 평가하게 하 였을 때 학습효과가 발생할 가능성을 사전에 예방하기 위해(Osberger, 1992), 6 명의 전문가들은 각각 17-18개의 대화 자료를 평가 하도록 하였다(Choi \& Lee, 2019).

\section{자료 분석}

음향학적 분석은 CSL을 사용하여 Shin 등(2016)과 Nadig와 Shaw (2012)의 분류기준을 참고하여 평균 음도, 음도 범위, 강도, 말 속도의 4 가지로 살펴보았다. 평균 음도는 아동이 산출한 5 개의 문 장에서 측정된 음도의 평균값으로 측정하였고, 음도 범위는 음도 의 최대값과 최소값의 차이로 계산하였다. 강도는 5 개의 문장에서 측정된 강도의 평균값으로 측정하였으며, 아동의 말속도는 음절수 를 발화지속시간(초)으로 나누는 초당음절수(syllable per second) 로 계산하였다.

지각적 평가 결과는 각 항목별 점수를 계산하였고, 아동별 문항 의 점수는 2 명의 평가자가 평가한 점수의 평균값으로 산출하였다.

\section{신뢰도}

6 명의 평가자가 공통적으로 평정한 4 개 대화 자료에 대한 지각적 평정 척도 결과의 평가자 간 신뢰도는 각 대화요소별 급내상관계수 (intraclass correlation coefficients)로 측정하였다. 신뢰도 측정 결 과 .948로 매우 높게 나타났으며, 문항별로 살펴보았을 때 목소리크 기(.525)를 제외한 모든 항목이 .84-.95로 나타났다. Nunnally (1978) 는 Cronbach 알파값이 .60 이상이면 신뢰할 수 있다고 하였는데, 대부분 .80-.90에 속하여 높은 신뢰도를 보인다고 해석할 수 있다.

\section{통계 처리}

자료의 통계 처리는 음향학적 분석과 지각적 평가 각각에서 고 기능 자폐스펙트럼장애 집단과 일반아동 집단 간 준언어적인 특성 에서 차이가 있는지 확인하기 위해 독립표본 $t$-검정을 실시하였다. 통계 분석에 사용한 프로그램은 SPSS version 25였다.

\section{연구결과}

\section{음향학적 분석을 통한 고기능 자폐스펙트럼장애 아동의 준언어적 특성}

음향학적 분석을 통해 고기능 자폐스펙트럼장애 집단과 일반아 
Table 2. Comparison of paralinguistic characteristics between HFASD and TD groups by acoustic analysis

\begin{tabular}{lccc}
\hline & HFASD $(\mathrm{N}=17)$ & $\mathrm{TD}(\mathrm{N}=34)$ & $t$ \\
\hline Mean pitch & $217.73 \pm 14.93$ & $213.51 \pm 20.20$ & .716 \\
Pitch variation range & $234.87 \pm 22.22$ & $228.49 \pm 19.99$ & .973 \\
Loudness & $55.83 \pm 6.74$ & $52.90 \pm 4.52$ & 1.734 \\
Speech rate & $3.94 \pm 1.28$ & $4.05 \pm 1.11$ & -.279 \\
\hline
\end{tabular}

Values are presented as mean \pm SD.

HFASD = high functioning autism spectrum disorders; TD = typical development.

동 집단의 대화에서의 준언어적 특성에서 어떠한 차이를 보이는지 살펴본 결과(Table 2), 평균음도( $(t=.716, p=.478)$, 음도 변화 $(t=.973$, $p=.336)$, 강도 $(t=1.734, p=.090)$, 말속도 $(t=-.279, p=.782)$ 모두 고 기능 자폐스펙트럼장애 집단과 일반아동 집단 간 유의한 차이를 보이지 않았다.

\section{지각적 평가를 통한 고기능 자폐스펙트럼장애 아동의 준언어적 특성}

지각적 평가를 통해 고기능 자폐스펙트럼장애 집단과 일반아동 집단의 대화에서의 준언어적 특성에서 어떠한 차이를 보이는지 살 펴본 결과(Table 3), 말속도 $(t=.761, p=0.451)$, 목소리 크기 $(t=1.225$, $p=0.227)$ 에서는 두 집단 간 유의한 차이를 보이지 않았으나, 목소 리 크기변화 $(t=3.242, p<.01)$, 목소리 높낮이 $(t=4.277, p<.001)$, 억양 $(t=5.010, p<.001)$ 에서는 두 집단 간 유의한 차이가 나타났다.

즉, 전문가들은 고기능 자폐스펙트럼장애 집단이 일반아동 집 단에 비해 목소리 크기변화가 부적절하며, 목소리 높낮이가 더 높 거나 낮고 억양이 부적절하다고 지각하였다.

\section{논의 및 결론}

본 연구는 고기능 자폐스펙트럼장애 아동의 대화에서의 준언어 적 특성을 음향학적 분석을 통해 살펴보고, 이러한 특성들이 다른 사람들에게도 어떻게 지각되는지 알아보기 위해 전문가 대상으로 지각적 평가를 실시하여 일반아동 집단과 어떠한 차이가 있는지 확인하고자 하였다.

먼저, 음향학적 분석을 통해 고기능 자폐스펙트럼장애 집단과 일반아동 집단 간 준언어적 측면에서 차이가 있는지 살펴본 결과, 평균 음도, 음도 범위, 강도, 말속도 모두 유의한 차이를 보이지 않 았다. 고기능 자폐스펙트럼장애 아동은 대화의 준언어적 요인인 평 균 음도, 음도 범위, 강도는 일반아동에 비해 높고 말속도는 느렸으 나 평균의 차이가 유의하게 크지 않았다. 이러한 결과는 고기능 자
Table 3. Comparison of paralinguistic characteristics between HFASD and TD groups by expert perceptual evaluation

\begin{tabular}{lccc}
\hline & HFASD $(\mathrm{N}=17)$ & $\mathrm{TD}(\mathrm{N}=34)$ & $t$ \\
\hline Speech rate & $0.56 \pm 0.92$ & $0.40 \pm 0.50$ & .761 \\
Voice loudness & $0.78 \pm 0.88$ & $0.50 \pm 0.68$ & 1.225 \\
Voice loudness variation & $0.72 \pm 0.83$ & $0.13 \pm 0.43$ & $3.242^{* *}$ \\
Voice pitch & $0.94 \pm 087$ & $0.17 \pm 0.38$ & $4.277^{* * *}$ \\
prosody & $1.00 \pm 0.91$ & $0.10 \pm 0.31$ & $5.010^{* * *}$ \\
\hline
\end{tabular}

Values are presented as mean \pm SD.

HFASD = high functioning autism spectrum disorders; TD = typical development. ${ }^{* *} p<.01,{ }^{* * *} p<.001$.

폐스펙트럼장애 아동이 다른 사람과 대화를 할 때 자신의 생활연 령과 언어연령에 적합한 수준으로 준언어적 요인을 사용할 수 있다 는 것을 의미한다.

말속도의 경우, 본 연구결과와 동일하게 일반아동과 유의한 차 이가 없다는 결과는 많은 선행연구에서 일관되게 보고되고 있다 (Diehl et al., 2009; Nadig \& Shaw, 2012). 말속도가 빠르면 화자가 전하고자 하는 내용이 빠르게 지나가기 때문에 말의 명료도가 떨 어져 대화 상대방의 이해력이 감소하게 되고, 말속도가 느리면 대 화 상대자가 화자의 말에 주의집중하기 어려워 대화에 영향을 미 칠 수 있다(Ahn, Shin, \& Kwon, 2002). 학령기 아동의 분당 말속도 는 평균 216.84, 즉 초당 말속도는 3.614로 보고되어(Moon \& Kwon, 2015), 본 연구에 참여한 두 집단 모두 연령의 말속도 범위에 속하 는 것으로 나타났다. 즉 고기능 자폐스펙트럼장애 아동의 말속도는 연령의 말속도 범위에 속하여 대화에 영향을 미치지 않을 수 있다.

말속도와는 달리 본 연구결과의 음도 범위(Nadig \& Shaw, 2012; Sharda et al., 2010), 음도와 강도(McAlpine et al., 2014; Sharda et al., 2010)에 대한 결과는 일부 선행연구들의 결과와 다르게 나타났 다. 이러한 차이는 측정방법과 언어적 차이로 해석해 볼 수 있다. 본 연구에서 음도 범위는 이전 선행연구들과 마찬가지로 최대 음도와 최저 음도의 차이로 측정하였다. 이는 높고 낮은 음도의 위치를 반 영해주지 못할 수 있으며 실제로 아동의 대화 안에서 사용되는 음 도 변화를 측정하는 데에는 한계가 있을 수 있다. 또한 문장유형에 따라서도 영향을 받을 수 있는데, 선행연구에서는 문장유형을 통 제하지 않고 가장 긴 발화를 추출하여 분석한 반면, 본 연구에서는 가장 긴 발화 5 개를 평서문과 의문문의 개수를 통제하여 추출하였 다. 두 번째로 선행연구들은 영어권 언어를 사용하는 자폐스펙트 럼장애 아동을 대상으로 실시된 것으로 강세로 품사를 구별하거나 중요한 부분을 강조하기 위해 사용하는 영어권과는 달리(Shin et al., 2016) 한국어에서는 억양 변화가 크지 않아 본 연구결과와 다른 결과를 보여짔을 가능성이 있다. 또한 본 연구에서는 대화에서의 
준언어적 특성을 살펴본 것으로 각 아동에게서 추출한 문장들의 내용이나 전후 관계, 사용된 어휘를 모두 통제하지 못하였는데, 이 러한 부분이 음향학적 분석 결과에 영향을 미쳤을 것으로 생각된 다. 따라서 대화에서의 준언어적 요인을 음향학적으로 측정하기 위 한 방법에 대해서는 더 검토하고 분석해 볼 필요가 있을 것이다.

다음으로 전문가를 대상으로 지각적 평가를 실시하여 고기능 자폐스펙트럼장애 집단과 일반아동 집단 간 준언어적 측면에서 차 이가 있는지 살펴보았다. 그 결과 고기능 자폐스펙트럼장애 집단과 일반아동 집단은 말속도와 목소리 크기에서 유의한 차이가 없었으 나, 목소리 크기변화, 목소리 높낮이(음도), 억양에서 집단 간 유의 한 차이가 나타났다. 이러한 결과는 전문가 집단이 고기능 자폐스 펙트럼장애 집단의 말속도와 목소리 크기는 일반아동과 크게 다르 지 않다고 지각하였으나, 목소리 크기변화가 약간 부자연스러우며, 목소리 높낮이(음도)는 약간 높고, 억양은 약간 부자연스럽게 지각 한다는 것을 나타내준다. 본 연구결과와 마찬가지로 지각적 평가를 활용한 선행연구들에서도 자폐스펙트럼장애 아동과 청소년들은 일반 집단에 비해 비전형적인 운율패턴을 보인다고 보고하였다 (Bauminger-Zviely et al., 2014; Nadig \& Shaw, 2012; Paul et al., 2009; Seo, 2013).

음향학적 분석을 통한 결과에서는 목소리 크기, 높낮이, 억양, 말 속도 모두에서 일반아동 집단과 차이를 보이지 않았으나 전문가들 은 지각적 평가에서 일반아동과 유의하게 다르다고 지각하였다. 이 러한 차이는 여러 가지 차원으로 해석해 볼 수 있다. 음향학적 분석 에서는 각 측정치를 기계를 사용하여 객관적으로 수치화하여 분 석하였다. 이에 반해 전문가 집단은 각 측정치에 대해 평가할 때 대 상자의 대화 내용이나 상황 등에 영향을 받아 평가할 수 있다(Na$\operatorname{dig} \&$ Shaw, 2012). 두 번째로 행동 분석에서 측정된 준언어적 요인 에서 집단 간 수치가 미미하게 나타났더라도 전문가 집단은 객관적 으로 측정된 수치의 미미한 차이를 일반아동과 다르게 지각할 수 있다. 특히 대화에서의 준언어적인 측면은 아동이 대화에서 언급하 고 있는 내용이나 전후 관계, 사용하고 있는 어휘 또는 아동의 정서 적 상태에 따라 영향을 받을 수 있기 때문에(Shriberg et al., 2001), 단순히 준언어적 요인의 객관적 수치가 전문가 집단에게 지각적으 로 평가되기 보다는 다른 여러 가지 요인들이 복합적으로 작용하 여 지각될 수 있음을 보여준다.

본 연구에서는 고기능 자폐스펙트럼장애 아동의 대화에서의 준 언어적 특성을 음향학적 분석과 전문가의 지각적 평가를 통해 살 펴보았다. 음향학적 분석을 통해 객관적 수치로 살펴보았을 때 고 기능 자폐스펙트럼장애 아동은 일반아동과 유의한 차이를 보이지 않았으나, 전문가 집단은 대화에서의 준언어적 측면에서 차이를 보
인다고 지각하였다. 즉 대화에서의 준언어적 특성을 살펴볼 때에서 는 단순히 수치만이 아닌 여러 가지 요인들이 복합적으로 작용할 수 있으며, 이러한 것들이 다른 사람들에게 지각되는 것에도 영향 을 미친다는 것을 의미한다. 따라서 지각적 평가를 통해 나타난 결 과는 고기능 자폐스펙트럼장애 아동의 운율 특성만을 평가했다고 단정짓기에는 어려울 수 있다. 하지만 고기능 자폐스펙트럼장애 아 동의 준언어적 특성들이 다른 사람과의 대화 시 부적절하게 지각되 는 것으로 나타났는데, 이러한 결과를 통해 고기능 자폐스펙트럼 장애 집단의 준언어적 측면의 평가와 중재가 필요하다는 것을 시사 하였다.

\section{REFERENCES}

Adams, C., Lockton, E., Freed, J., Gaile, J., Earl, G., McBean, K., ... \& Law, J. (2012). The Social Communication Intervention Project: a randomized controlled trial of the effectiveness of speech and language therapy for schoolage children who have pragmatic and social communication problems with or without autism spectrum disorder. International Journal of Language \& Communication Disorders, 47(3), 233-244.

Ahn, J. B., Shin, M. S., \& Kwon, D. H. (2002). The study of speech rate in normal-speaking adults and children. Speech Sciences, 9(4), 93-103.

Bauminger-Zviely, N., Karin, E., Kimhi, Y., \& Agam-Ben-Artzi, G. (2014). Spontaneous peer conversation in preschoolers with high-functioning autism spectrum disorder versus typical development. Journal of Child Psychology and Psychiatry, 55(4), 363-373.

Bishop, D. (2013). Children's Communication Checklist (CCC-2) (pp. 614618). Springer New York.

Choi, J., \& Lee, Y. (2013). Conversational turn-taking and topic manipulation skills of children with high-functioning autism spectrum disorders. Communication Sciences \& Disorders, 18(1), 12-23.

Choi, J., \& Lee, Y. (2015). Contingency and informativeness of topic maintenance in children with high-functioning autism spectrum disorders. Communication Sciences \& Disorders, 20(3), 413-423.

Choi, J., \& Lee, Y. (2019). Conversational factors discriminating between highfunctioning autism spectrum disorders and typical development: perceptual rating scale. Communication Sciences \& Disorders, 24(2), 343-353.

Diehl, J. J., Watson, D., Bennetto, L., McDonough, J., \& Gunlogson, C. (2009). An acoustic analysis of prosody in high-functioning autism. Applied Psycholinguistics, 30(3), 385-404.

Ferrand, C. T. (2011). Voice disorders: scope of theory and practice. Boston, 


\section{MA: Pearson.}

Heo, H., \& Lee, Y. K. (2012). Conversational turn-taking and topic manipulation skills in conversations of school-age low-achievers in language learning. Korean Journal of Communication \& Disorders, 17(1), 66-78.

Hoff, E. (2009). Language development (5th ed.). Belmont, CA: Wadsworth Publishing.

Jung, K. S., \& Seong, C. J. (2007). A comparative study of the prosodic features between autism spectrum disorder and normal children in Korean read sentence. Korean Journal of Communication \& Disorders, 12(4), 625642.

Kim, Y. T., Hong, G. H., Kim, K. H., Jang, H. S., \& Lee, J. Y. (2009). Receptive \& expressive vocabulary test (REVT). Seoul: Seoul Community Rehabilitation Center.

Landa, R., Piven, J., Wzorek, M. M., Gayle, J. O., Chase, G. A., \& Folstein, S. E. (1992). Social language use in parents of autistic individuals. Psychological Medicine, 22(1), 245-254.

Lee, Y., Heo, H., \& Jang, S. (2015). Language Scale for School-aged Children (LSSC). Seoul: Hakjisa.

Lee, Y., \& Choi, J. (in press). Hallym Conversation and Pragmatic Assessment Protocol. Manuscript in preparation.

Lee, Y. \& Lee, H. (2013). Conversational turn-taking of toddlers with language delay. Special Education Research, 12(3), 357-377.

Lim, S. M., \& Sim, H. S. (2009). Prosodic control of high functioning autism and normal children in relation to question-statement contrast. Journal of the Korean Association for Persons with Autism, 9(1), 37-55.

Lord, C., Rutter, M., DiLavore, P., Risi, S., Gotham, K., \& Bishop, S. (2012). Autism Diagnostic Observation Schedule-2nd edition (ADOS-2). Los Angeles, CA: Western Psychological Corporation.

McAlpine, A., Plexico, L. W., Plumb, A. M., \& Cleary, J. (2014). Prosody in young verbal children with autism spectrum disorder. Contemporary Issues in Communication Science \& Disorders, 41, 120-132.

McCann, J., Peppé, S., Gibbon, F. E., O’Hare, A., \& Rutherford, M. (2007). Prosody and its relationship to language in school-aged children with highfunctioning autism. International Journal of Language \& Communication Disorders, 42(6), 682-702.

Meharabian, A. (1981). Silent messages. California: Wadsworth.

Moon, J. E., \& Kwon, D, H. (2015). A study of school-aged children's speech rates and disfluency characteristics depending on grades. Journal of Speech \& Hearing Disorders, 24(1), 113-121.

Nadig, A., \& Shaw, H. (2012). Acoustic and perceptual measurement of ex- pressive prosody in high-functioning autism: increased pitch range and what it means to listeners. Journal of Autism and Developmental Disorders, 42(4), 499-511.

Nippold, M. A., Hesketh, L. J., Duthie, J. K., \& Mansfield, T. C. (2005). Conversational versus expository discourse. Journal of Speech, Language, and Hearing Research, 48(5), 1048-1064.

Nunnally, J. C. (1978). Psychometric theory (2nd ed.). New York, NY: McGrawHill.

Osberger, M. J. (1992). Scaling procedures for the measurement of speech intelligibility. In R. D. Kent (Ed.), Intelligibility in speech Disorders (pp. 233263). Philadelphia: John Benjamins.

Park, H. (2014). Korean version of Comprehensive Test of Nonverbal Intelligence Second Edition (K-CTONI-2). Seoul: Mindpress.

Park, Y. J., Choi, J., \& Lee, Y. (2017). Development of topic management skills in conversation of school-aged children. Communication Sciences \& Disorders, 22(1), 25-34.

Paul, R., Orlovski, S. M., Marcinko, H. C., \& Volkmar, F. (2009). Conversational behaviors in youth with high-functioning ASD and Asperger syndrome. Journal of Autism and Developmental Disorders, 39(1), 115-125.

Prutting, C. A., \& Kittchner, D. M. (1987). A clinical appraisal of the pragmatic aspects of language. Journal of Speech and Hearing Disorders, 52(2), 105-119.

Seo, G. H. (2013). Characteristics of nonverbal communication behaviors in adolescents with high functioning autism and Asperger disorder. Journal of Emotional \& Behavioral Disorders, 29(1), 73-106.

Sharda, M., Subhadra, T. P., Sahay, S., Nagaraja, C., Singh, L., Mishra, R., ... \& Singh, N. C. (2010). Sounds of melody: pitch patterns of speech in autism. Neuroscience Letters, 478(1), 42-45.

Shin, H. B., Choi, J., \& Lee, Y. (2016). Prosodic pattern of the children with high-functioning autism spectrum disorder according to sentence type. Phonetics and Speech Sciences, 8(2), 65-71.

Shin, H. B., Choi, J., Kim, K., \& Lee, Y. (2015). Expressive prosody in autism spectrum disorders: meta-analysis. Communication Sciences \& Disorders, 20(3), 424-434.

Shriberg, L. D., Paul, R., McSweeny, J. L., Klin, A., Cohen, D. J., \& Volkmar, F. R. (2001). Speech and prosody characteristics of adolescents and adults with high-functioning autism and Asperger syndrome. Journal of Speech, Language, and Hearing Research, 44(5), 1097-1115.

Tantum, D., Holmes, D., \& Cordess, C. (1993). Nonverbal expression in autism of Asperger type. Journal of Autism and Developmental Disorders, 
23(1), 111-133.

Van Bourgondien, M. E., \& Woods, A. V. (1992). Vocational possibilities for high-functioning adults with autism. In High-functioning individuals with autism (pp. 227-239). Springer US.

Van Santen, J. P., Prud'Hommeaux, E. T., Black, L. M., \& Mitchell, M. (2010). Computational prosodic markers for autism. Autism, 14(3), 215-236.

Yang, Y., Lee, Y., Choi, J., \& Yoon, J. (2018). Development of conversational skills from late children to adolescent. Communication Sciences \& Disor- ders, 23(2), 270-278.

Yoo, H. J. (2008). Korean version of social communication questionnaire. Seoul: Hakjisa.

Yoon, M., Lee, Y., \& Sim, H. S. (2000). The relationship between speech intelligibility and related factors of speakers in prelingually hearing impaired children using hearing aids. Korean Journal of Communication \& Disorders, 5(2), 144-158. 
Appendix 1. 준언어적 특성에 대한 지각적 평정 청도 항목

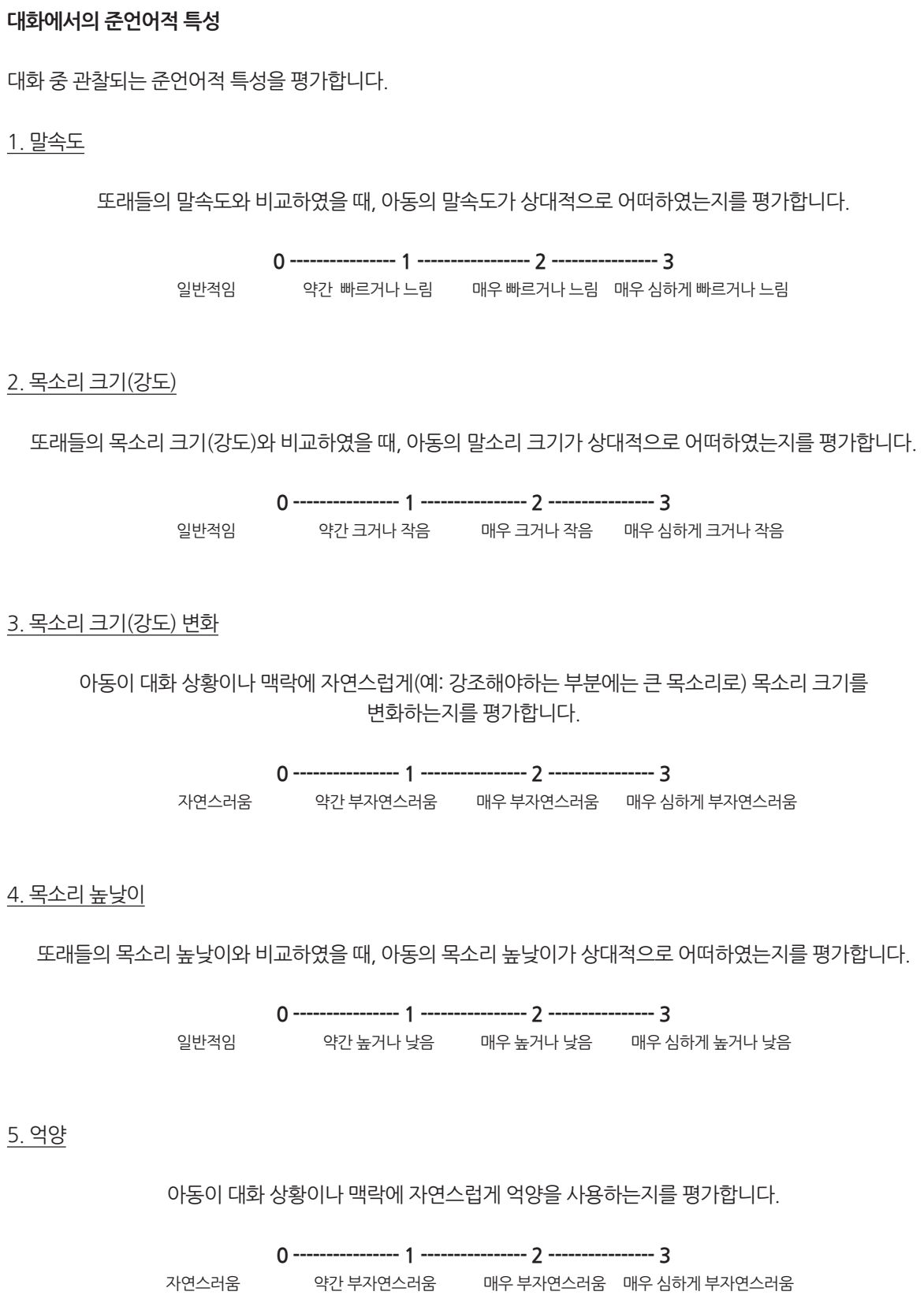

Choi \& Lee (2019) 지각적 평정 척도 일부. 


\title{
국문초록
}

\author{
고기능 자폐스펙트럼장애 아동의 대화에서의 준언어적 특성: 전문가 지각적 평가와 음향학적 분석 결과 비교 \\ 최지은 1 이윤경 ${ }^{2}$ \\ 1한림대학교 보건과학대학원 언어병리학과, ${ }^{2}$ 한림대학교 언어청각학부
}

배경 및 목적: 자폐스펙트럼장애 아동의 비전형적인 준언어적 특성은 다른 사람과의 대화시 의미 전달에 부정적인 영향을 줄수 있고, 더 나아가 의사소통 의도가 제대로 전달되는 것을 방해할 수 있다. 본 연구에서는 고기능 자폐스펙트럼장애 아동의 대화에서의 준언어 적 특성을 음향학적 분석을 통해 살펴보고, 이러한 특성이 다른 사람에게도 어떻게 지각되는지 알아보기 위해 전문가를 대상으로 지 각적 평가를 실시하여 확인하고자 하였다. 방법: 연구 대상은 학령기 고기능 자폐스펙트럼장애 아동 17 명과 일반아동 34 명(생활연령 일치, 언어연령 일치 각 17 명씩)이었다. 음향학적 분석에 사용한 모든 아동의 발화는 평서문 3 개, 의문문 2 개를 대화 자료 안에서 추출하 였으며, 평균 음도, 음도 범위, 강도, 말속도를 분석하였다. 지각적 평가를 위해 모든 대화 자료는 무선적으로 배치하여 언어재활사 전문 가 6명에게 제시한 후, 지각적 평정 척도를 활용하여 평가하도록 하였다. 결과: 음향학적 분석 결과, 평균 음도, 음도 범위, 강도, 말속도 모두 집단 간 유의한 차이를 보이지 않았다. 이에 반해 지각적 평가 결과 전문가 집단은 고기능 자폐스펙트럼장애 집단이 일반아동 집 단에 비해 목소리 크기 변화와 억양이 부자연스럽고, 목소리가 높다고 지각하였다. 논의 및 결론: 연구 결과에 따라 고기능 자폐스펙트 럼장애 집단의 대화에서의 준언어적 특성에 대해 논의하였다.

핵심어: 지각적 평가, 음향학적 분석, 고기능 자폐스펙트럼장애, 준언어적 특성, 대화

본 논문은 제 1 저자의 박사학위논문(2019)의 일부를 발췌한 것임.

\section{참고문헌}

김영태, 홍경훈, 김경희, 장혜성, 이주연(2009). 수용·표현어휘력검사(REVT). 서울: 서울장애인종합복지관.

문지은, 권도하(2015). 학령기 아동의 학년별 말 속도 및 비유창성 특성. 언어치료연구, 24(1), 113-121.

박윤정, 최지은, 이윤경(2017). 초등학생 아동의 대화주제관리 능력의 발달. Communication Sciences \& Disorders, 22(1), 25-34.

박혜원(2014). 한국 비언어지능검사 2판(K-CTONI-2). 서울: 마인드프레스.

서경희(2013). 고기능 자폐장애 청소년과 아스퍼거장애 청소년의 비언어적 의사소통 특성. 정서.행동장애연구, 29(1), 73-106.

신희백, 최지은, 김기숙, 이윤경(2015). 자폐스펙트럼장애의 운율 표현에 대한 메타분석. Communication Sciences \& Disorders, 20(3), 424-434.

신희백, 최지은, 이윤경(2016). 문장유형에 따른 고기능 자폐스펙트럼장애 아동의 운율 특성. 말소리와음성과학, 8(2), 65-71

안종복, 신명선, 권도하(2002). 정상 성인 및 아동의 구어속도에 관한 연구. 음성과학, 9(4), 93-103.

양예원, 이윤경, 최지은, 윤지혜(2018). 후기 아동기에서 청소년기까지의 대화발달. Communication Sciences \& Disorders, 23(2), 270-278.

유희정(2008). 한국판사회적 의사소통 설문지(SCQ). 서울: 학지사

윤미선, 이윤경, 심현섭(2000). 청각장애아동의 말명료도에 영향을 미치는 화자요인. 언어청각장애연구, 5(2), 144-158.

이윤경, 이효주(2013). 표현언어발달지체 영유아의 대화차례 주고받기 특성. 특수교육, 12(3), 357-377.

이윤경, 허현숙, 장승민(2015). 학령기 아동 언어검사(LCCS). 서울: 학지사.

임세미, 심현섭(2009). 의문문과 평서문 읽기과제를 통한 고기능 자폐아동과 일반아동의 운율 통제능력 비교. 자폐성장애연구, 9(1), 37-55.

정금수, 성철재(2007). 자폐범주성 장애아동과 정상아동의문장 읽기에서의 운율특성 비교. 언어청각장애연구, 12(4), 625-642.

최지은, 이윤경(2013). 학령기 고기능 자폐범주성장애 아동의 대화차례 주고받기 및 주제운용능력. Communication Sciences \& Disorders, 18(1), 12-23.

최지은, 이윤경(2015). 학령기 고기능 자폐스펙트럼장애 아동의 주제유지능력. Communication Sciences \& Disorders, 20(3), 413-423. 
최지은, 이윤경(2019). 학령기 고기능 자폐스펙트럼장애 아동을 판별하는 언어적, 비언어적 대화 요인: 지각적 평가를 중심으로. Communication Sciences \& Disorders, 24(2), 343-353.

허현숙, 이윤경(2012). 언어학습부진아동의 대화차례 주고받기 및 주제운용 특성. 언어청각장애연구, 17(1), 66-78.

\section{ORCID}

최지은(제1저자, https://orcid.org/0000-0002-4141-4096); 이윤경(교신저자, https://orcid.org/0000-0002-9759-6247) 